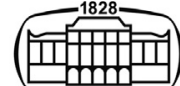

AKADÉMIAI KIADÓ

\section{Acta Veterinaria} Hungarica

$68(2020) 1,53-58$

DOI:

10.1556/004.2020.00016

(c) 2020 Akadémiai Kiadó, Budapest

\section{ORIGINAL ARTICLE}

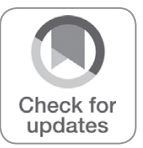

*Corresponding author. Tel./fax: 0081 (11) 3884702. E-mail: kazuyuki@rakuno.ac.jp

\title{
Serum iron concentration in cattle with endotoxaemia
}

KENJI TSUKANO, TOSHIO SHIMAMORI and
KAZUYUKI SUZUKI*

School of Veterinary Medicine, Rakuno Gakuen University, 582 Midorimachi, Bunnkyoudai, Ebetsu, Hokkaido, 069-8501, Japan

Received: August 27, $2019 \bullet$ Accepted: January 24, 2020

Published online: May 8, 2020

\section{ABSTRACT}

The objective of this study was to examine whether serum iron $(\mathrm{Fe})$ concentration is useful as a prognostic biomarker for cows with acute coliform mastitis (ACM). Our study was composed of determining the reproducibility of serum Fe concentration as a prognostic criterion in cows with ACM (Study 1) and clarifying the sequential changes in serum Fe concentration in cattle that received endotoxin (Study 2). Seventy-seven cows with $(\mathrm{n}=47)$ or without $(\mathrm{n}=30)$ ACM were enrolled in Study 1 . The proposed diagnostic cut-off value of serum Fe concentration indicating a poor prognosis of $\mathrm{ACM}$ based on the analysis of the receiver operating characteristic curves was $<31.5 \mu \mathrm{g} / \mathrm{dL}$. Ten young cattle aged $176.8 \pm 23.7$ days were enrolled in Study 2. Five young cattle received endotoxin (LPS group) and the remaining five received physiological saline (control group). Blood collections were carried out before endotoxin challenge (pre), and $0.5,1,2,4,8,12,24$, and $48 \mathrm{~h}$ after the challenge. As a result, a significant decrease in serum Fe concentration was not observed until $24 \mathrm{~h}$ after endotoxin challenge. Because in cows with clinical ACM it is difficult to know the time course after infection, the alteration in serum Fe concentrations alone may be an insufficient prognostic criterion.

\section{KEYWORDS}

acute coliform mastitis, cattle, endotoxin, hepcidin, iron

\section{INTRODUCTION}

Acute coliform mastitis (ACM) is the main cause of moderate to severe clinical mastitis in dairy farms (Hillerton and Berry, 2005). Escherichia coli (E. coli) and Klebsiella pneumoniae (K. pneumoniae), in particular, are most commonly isolated from cows with ACM (Hogan and Smith, 2003). Endotoxin is released from Gram-negative bacteria at the time of bacterial cell death, initiating an inflammatory response. Systemic signs of ACM include diarrhoea, inhibition of rumen motility, paralysis, hypothermia, very high pulse rate and hypersalivation. It is well recognised that the severity of coliform mastitis determines the outcome of the disease as well as the degree of production loss. Therefore, accurate evaluation of the severity in the field is needed to determine appropriate treatment for ACM. Unfortunately, despite appreciable efforts to introduce clear definitions and scoring based on systemic signs (Wenz et al., 2001), there is still some confusion in the field.

Iron $(\mathrm{Fe})$ is known to play many roles in enzymatic activity, and is an essential trace element for the host and pathogen (Ong et al., 2006). Fe concentration decreases rapidly in response to inflammation and this can be explained as the host's defence mechanism (Borges et al., 2007). A low-Fe environment, which is a consequence of Fe sequestration in the body for the control of bacterial proliferation, is essential for the bacteriostatic system to operate in the body (Ward et al., 1996). This reduction was attributed to lower intestinal absorption and a reduction in the release of Fe by reticuloendothelial cells (Andriopoulos et al., 2009; Cherayil, 2011; Cherayil et al., 2011). It is well known that hepcidin is essential for systemic Fe homeostasis. Hepcidin is predominantly secreted by hepatocytes in response to inflammation (Przybylowski et al., 2013), 
and its major function is to sequester Fe (Zhang, 2010). Interleukin-6 (IL-6) was identified as an important upstream mediator of hepcidin induction by inflammation (Nemeth et al., 2003). The utility of serum Fe concentration for evaluating the severity of cows with ACM has been reported previously (Lohuis et al., 1990; Erskine and Bartlett, 1993; Borges et al., 2007; Baydar and Dabak, 2014). Although most of these reports showed the relationship between cows with ACM and blood Fe concentrations, few studies have investigated the relationship between prognosis and blood Fe concentrations in cows with ACM. For instance, Shimamori et al. (2017) proposed a diagnostic cut-off value for serum $\mathrm{Fe}$ concentrations of $<82.0 \mu \mathrm{g} / \mathrm{d} l$ based on receiver operating characteristic (ROC) curves in order to identify cows with a poor prognosis. The area under the curve (AUC) for serum Fe concentrations was 0.713 , and the sensitivity and specificity of the proposed diagnostic cut-off value for serum Fe concentrations were $77.8 \%$ and $77.0 \%$, respectively, which means a moderate diagnostic ability. Therefore, further studies are needed to improve prognostic criteria of serum Fe concentration in cows with ACM. Namely, the current prognostic criteria of serum Fe concentration in cows with ACM need confirmation of reproducibility. Furthermore, in order to improve the diagnostic ability, clarifying the variations in serum Fe concentration after endotoxin shock seems to be useful for the interpretation of the measured values.

The objective of this study was to examine whether the serum Fe concentration is useful as a prognostic biomarker for cows with ACM. Our study was composed of determining the reproducibility of serum Fe concentration as a prognostic criterion in cows with ACM (Study 1) and clarifying the sequential changes in serum Fe concentration in cattle that received endotoxin (Study 2).

\section{MATERIALS AND METHODS}

All procedures were performed in accordance with the Guide for the Care and Use of Laboratory Animals of the School of Veterinary Medicine at Rakuno Gakuen University (Approval\#: VC15H2) and the National Research Council (2011). The present study consisted of clinical trials using cows with ACM and an endotoxin-challenge model using healthy young cattle.

\section{Study 1: clinical trial for acute coliform mastitis (ACM)}

A prospective case-control study was performed using cows with or without ACM. ACM was diagnosed on the basis of clinical examination by veterinary practitioners. Cows with multiple quarter infections were included in this study. Quarter milk samples were collected when clinical mastitis was first observed. All quarter milk samples were stored at $-20{ }^{\circ} \mathrm{C}$ until culturing. The quarter milk samples were measured as follows. First, $10 \mu \mathrm{L}$ of each milk sample was plated on a $5 \%$ sheep blood agar plate (Nihon Becton, Dickinson and Company, Tokyo, Japan). Then, after $24 \mathrm{~h}$ of incubation at $37{ }^{\circ} \mathrm{C}$, each plate was inspected for bacterial growth, which was presumptively identified as coliform by colony characteristics. To further characterise the isolates and to distinguish between E. coli and K. pneumoniae, the India ink capsule stain was performed. All cows were treated intravenously with $5.0 \mathrm{~mL} / \mathrm{kg}$ of $7.2 \%$ hypertonic saline solution (Koutyosyokueneki V-injection, Nippon Zenyaku Kogyo Co., Fukushima, Japan), and were administered $10 \mathrm{mg} / \mathrm{kg}$ of kanamycin sulfate (Meiji Seika, Co., Tokyo, Japan) as a first-line antibiotic treatment. The prognosis was divided into good or poor based on the outcome of medical treatment. Therefore, the poor prognosis group was composed of cows that died of, or were euthanised due to, ACM within 7 days after the first medical examination. Fortyseven Holstein-Friesian cows with ACM were enrolled in this clinical trial. Of the 47 dairy cows, the good and poor prognosis groups comprised 30 and 17 cows, respectively. As controls, 30 healthy cows with no clinical signs of mastitis were kept at the School of Veterinary Medicine, Rakuno Gakuen University.

On the first clinical examination day, $10 \mathrm{~mL}$ of whole blood was collected via jugular venipuncture into separate serum tubes immediately before administering medications. After centrifugation at $3,000 \times \mathrm{g}$ for $15 \mathrm{~min}$ at room temperature, the samples were stored at $-80{ }^{\circ} \mathrm{C}$ until analysis. Serum Fe concentrations were measured by the 2-nitroso5-( $N$-propyl- $N$-sulphopropylamino)phenol (nitroso-PSAP) method using an auto-analyzer (LABOSPEC 003, Hitachi Medical, Co., Japan) at an OD of $753 \mathrm{~nm}$ with a commercial kit (N-assay L Fe-H Nittobo, Nitto Boseki, Co. Ltd., Tokyo, Japan). The nitroso-PSAP method for measuring serum Fe was described previously (Hirayama and Nagasawa, 2017). Duplicate measurements were performed, and the mean Fe concentration was used for further statistical analyses.

\section{Study 2: endotoxin challenge model}

A randomised clinical trial (stratified randomisation) was performed. Five female and five male young Holstein cattle, aged $176.8 \pm 23.7$ days and weighing $178.7 \pm 33.3 \mathrm{~kg}$, were enrolled in this study. These young cattle were kept at the School of Veterinary Medicine, Rakuno Gakuen University for research purposes. All cattle were clinically normal before the experiment based on physical examination, nutritional status, feed and water intake, urine and faeces production, and haematological analysis. A complete, balanced growth diet consisting of pelleted concentrate rations and mixed grass hay was provided, and the cattle had unlimited access to fresh water.

All cattle were fitted with an indwelling jugular catheter immediately before the initiation of endotoxin or physiological saline infusion. A preliminary study found that endotoxin activity in physiological saline solution was below the detection limit. Young cattle in the LPS (three Holstein males and two Holstein females) and the control (two Holstein males and three Holstein females) groups received $2.5 \mu \mathrm{g} / \mathrm{kg}$ intravenous bolus doses of O111:B4 LPS (L4391, Sigma-Aldrich, St. Louis, MO, USA) in $10 \mathrm{~mL}$ of serum or physiological saline (Physiological saline, Nippon Zenyaku 
Kogyo Co. Ltd., Fukushima, Japan) via the jugular vein, respectively. Blood samples $(10 \mathrm{~mL})$ were withdrawn from the contralateral jugular vein before endotoxin challenge (pre), and $0.5,1,2,4,8,12,24$, and $48 \mathrm{~h}$ after the challenge. Serum and plasma were separated after centrifugation at $3,000 \times \mathrm{g}$ for $15 \mathrm{~min}$ at room temperature, and stored at $-80{ }^{\circ} \mathrm{C}$ until analysis.

Ultrasound-guided liver biopsy was carried out at the $10^{\text {th }}$ and $11^{\text {th }}$ intercostal spaces at pre, and $0.5,1,2,4,8,12$, 24 , and $48 \mathrm{~h}$ after the challenge using a 14-G, 13-mm-notch biopsy needle (Quick-cut C2, Hakko, Tokyo, Japan) under local anaesthesia with $2.5 \mathrm{ml}$ of $2 \%$ lidocaine (Xylocaine injection 2\%, AstraZeneca, Osaka, Japan). Hepatic specimens obtained by liver biopsy were immediately soaked in RNAlater RNA stabilisation reagent (Qiagen, Hilden, Germany), and then homogenised using a rotor-stator homogeniser with a disposable head (bio-masher II, Wako, Tokyo, Japan) within $24 \mathrm{~h}$ after collection. Total RNA was extracted using the High Pure RNA Tissue Kit (Roche Diagnostics, Basel, Switzerland) and stored at $-80{ }^{\circ} \mathrm{C}$ until analysis.

Immediately before being used in the assays, plasma samples were diluted 20-fold in endotoxin-free water (Sterile Water for Irrigation USP, Otsuka Pharmaceutical Co. Ltd., Tokyo, Japan) and agitated in a vortex for $10 \mathrm{sec}$. Then, the specimens were heated for $10 \mathrm{~min}$ at $80{ }^{\circ} \mathrm{C}$ to inactivate the interfering substances. Plasma endotoxin activity was detected using the Limulus amebocyte lysate turbidimetric assay (LAL-KTA). Endotoxin-free water was used as the blank in all tests. The endotoxin reference standard (CSE, Control Std Endotoxin, Charles River, Charleston, SC, USA), which contained 10,000 endotoxin units (EU)/vial, was used as the positive control. The LAL reagent for KTA (Endosafe ${ }^{\circledR} \mathrm{KTA}^{2}$, Charles River, Charleston, SC, USA) was reconstituted with Endotoxin-Specific Buffer Solution (Charles River) to eliminate the interference of beta-glucan in the samples. This traditional LAL assay was performed on a 96-well microplate (Endosafe ${ }^{\circledR}$ 96-well, flat bottom microplate M9001, Charles River) using a microplate reader (Sunrise $^{\mathrm{TM}}$, Tecan Group Ltd., Männedorf, Switzerland) and EndoScan- $\mathrm{V}^{\mathrm{TM}}$ endotoxin-measuring software (Charles River). A standard curve was established for each assay in the range between $0.003 \mathrm{EU} / \mathrm{mL}$ and $3.0 \mathrm{EU} / \mathrm{mL}$, according to the package insert of the LAL product. The lower limit of detection for this assay was $0.028 \mathrm{EU} / \mathrm{mL}$.

The mRNA expression levels of hepcidin and IL- 6 in the liver obtained from endotoxin-challenged cattle were measured using real-time PCR (Light-Cycler 480 system II, Roche Diagnostics, Basel, Switzerland). Both reverse transcription and real-time PCR were carried out using one-step methods with commercial kits (Light-Cycler ${ }^{\circledR}$ Multiplex RNA Virus Master version 3, Roche Diagnostics). The realtime PCR reaction was performed in 96-well plates with a final volume of $20 \mu \mathrm{L}$. The PCR mixture contained $5 \mu \mathrm{L}$ of template RNA, $1 \mu \mathrm{L}(0.5 \mu \mathrm{M})$ of each primer (forward and reverse), $0.4 \mu \mathrm{L}$ of universal probe, $4 \mu \mathrm{L}$ of RT-PCR reaction mix, $0.1 \mu \mathrm{L}$ of RT-Enzyme solution, and $8.5 \mu \mathrm{L}$ of water. Primers for PCR amplification of bovine hepcidin and IL-6 were designed by commercial software (E-method, Roche
Diagnostics), and primers and the universal probe for bovine hepcidin and IL-6 are shown in Table 1. Amplification conditions for all assays were $50{ }^{\circ} \mathrm{C}$ for $10 \mathrm{~min}, 95{ }^{\circ} \mathrm{C}$ for $30 \mathrm{sec}, 45$ cycles of $95{ }^{\circ} \mathrm{C}$ for $5 \mathrm{sec}$, and $60{ }^{\circ} \mathrm{C}$ for $30 \mathrm{sec}$ following the manufacturer's instructions. The results of relative quantification per Glyceraldehyde 3-phosphate dehydrogenase (GAPDH) mRNA as a reference gene were automatically provided using commercial software (Emethod, Roche Diagnostics). We calculated using threshold cycle of target and reference mRNA (target/reference) to determine relative expression levels. The serum Fe concentrations were measured as described above.

\section{Statistical analysis}

Statistical analyses were performed using a commercial software package (IBM SPSS Statistics, v.21, IBM Co, Somers, NY, USA). Normally distributed data are reported as the mean \pm standard deviation (SD), and non-normally distributed data are expressed as the median and range. In Study 1, the serum Fe concentrations among groups were compared by the Tukey HSD test. In addition, ROC curves were used to characterise the sensitivity and specificity of the serum Fe concentration for detecting a poor prognosis in cattle with ACM. The optimal cut-off point for a test was calculated by the Youden index (Akobeng, 2007). The Youden index (J) is defined as the maximum vertical distance between the ROC curve and the diagonal or chance line, and is calculated as $\mathrm{J}=$ maximum [sensitivity+specificity-1]. The cut-off point on ROC curves that corresponds to J was considered the optimal cut-off point (Akobeng, 2007). In Study 2, we processed plasma endotoxin activity, serum Fe concentrations, mRNA expression levels of hepcidin and IL-6 for each dependent variable (group and times) by two-way repeated-measures ANOVA. The mean values for each dependent variable were compared with the pre values using Dunnett's $t$-test after two-way repeated measures ANOVA as the $F$ test. The significance level was $P<0.05$.

\section{RESULTS}

\section{Study 1: clinical trial for acute coliform mastitis (ACM)}

Klebsiella pneumoniae was isolated from raw milk in 10 out of the 47 cows, and the remaining cows had mastitis due to

Table 1. List of primers and universal probes for bovine hepcidin, IL-6, and GAPDH

\begin{tabular}{ccccc}
\hline Primer & & Length & Sequence & $\begin{array}{c}\text { Universal } \\
\text { probe }\end{array}$ \\
\hline Hepcidin & Left & 19 & cctgccttctgctccttgt & $\# 111$ \\
& Right & 20 & ctgtgagctgtcgtgtctgg & \\
IL-6 & Left & 19 & cactccattcgctgtctcc & $\# 9$ \\
& Right & 24 & ggtgtcattttgaaatcttctcc & \\
GAPDH & Left & 20 & cacagtcaaggcagagaacg & $\# 9$ \\
& Right & 20 & ccacttgatgttggcaggat & \\
\hline
\end{tabular}


E. coli. However, there were no significant differences in prognosis or serum Fe concentration between them.

The cows with ACM in the good $(60.8 \mu \mathrm{g} / \mathrm{dL}$, min to $\max$ $1-155 \mu \mathrm{g} / \mathrm{dL}, P=0.0000000051028)$ and poor prognosis (17.9 $\mu \mathrm{g} / \mathrm{dL}$, min to $\max 3-56 \mu \mathrm{g} / \mathrm{dL}, P=0.0000000051008)$ groups had lower serum Fe concentrations than those without mastitis $(149.9 \mu \mathrm{g} / \mathrm{dL}$, min to $\max 95-226 \mu \mathrm{g} / \mathrm{dL}$, Fig. 1). In addition, the serum Fe concentration was significantly lower in cows with a poor prognosis than in those with a good prognosis $(P=0.000440)$. The AUC for the serum Fe concentration was $0.781(P=0.00000016538)$. The proposed diagnostic cut-off for serum Fe concentration for a poor ACM prognosis based on the ROC curves was $<31.5 \mu \mathrm{g} / \mathrm{dL}$. The sensitivity and specificity of the proposed diagnostic cut-offs for serum $\mathrm{Fe}$ concentration were $73.3 \%$ and $94.1 \%$, respectively.

\section{Study 2: endotoxin challenge model}

The sequential changes in plasma endotoxin activity and serum Fe concentration in the cattle that received endotoxin or physiological saline are shown in Fig. 2. The pre values of plasma endotoxin activity were not detected in any of the cattle (lower limit: $0.028 \mathrm{EU} / \mathrm{mL}$ ). There was a significant and progressive increase in plasma endotoxin activity to $1.239 \pm 0.881 \mathrm{EU} / \mathrm{mL}$ at $30 \mathrm{~min}$ after endotoxin challenge $(P=0.000005)$, and the level then returned to the pre value at $4 \mathrm{~h}$ after endotoxin challenge. However, there were no significant sequential changes in the plasma endotoxin activity in the control group. Sequential changes in serum $\mathrm{Fe}$ concentration were monitored in cattle that received endotoxin or physiological saline. The $2.5 \mu \mathrm{g} / \mathrm{kg}$ O111B4 LPS infusion induced a significant and progressive increase in serum Fe concentration to $207.4 \pm 46.6 \mu \mathrm{g} / \mathrm{dL}$ at $4 \mathrm{~h}$ after endotoxin challenge, and the concentration returned to the pre value at $8 \mathrm{~h}$ after endotoxin administration. The Fe concentration in serum then significantly decreased to 30.4 $\pm 15.7 \mu \mathrm{g} / \mathrm{dL}$ at $24 \mathrm{~h}$ after endotoxin challenge $(P=$ $0.000179)$. The significantly low serum Fe level in the cattle

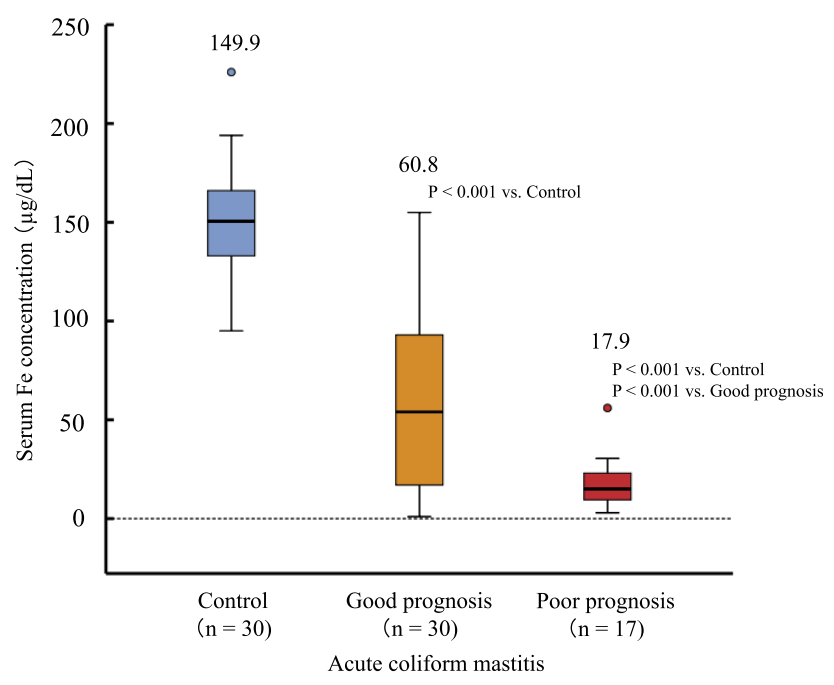

Figure 1. Comparison of serum iron concentrations among groups by the Tukey HSD test
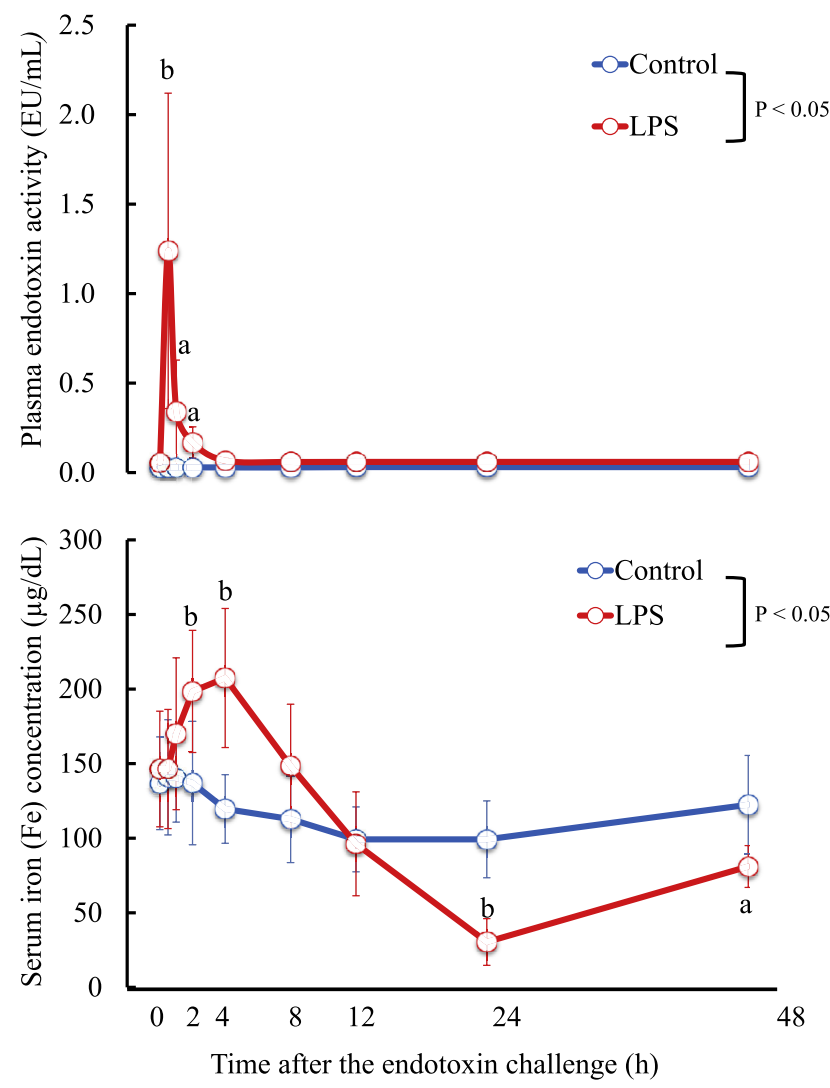

Figure 2. Sequential changes in plasma endotoxin activity and iron (Fe) concentrations in the endotoxin challenge model. a, vs. pre $P<0.05 ; \mathrm{b}$, vs. pre $P<0.01$ by Dunnett's $t$-test after two-way repeated ANOVA as the F test. Red line: LPS group, blue line: control group

was maintained from 24 to $48 \mathrm{~h}$ after endotoxin administration as compared with the pre value $(P<0.001)$.

The sequential changes in the expression of IL-6 and hepcidin mRNA in the cattle that received endotoxin is shown in Fig. 3. In hepatic tissues, significantly high expression of IL- 6 mRNA in cattle was observed $2 \mathrm{~h}$ after endotoxin challenge as compared with the pre values $(P=0.018)$. The expression of hepatic hepcidin mRNA in the cattle was significantly higher $4(P=0.00000000304)$ and $8 \mathrm{~h}(P=0.00000000236)$ after endotoxin challenge as compared with the pre values.

\section{DISCUSSION}

In Study 1, we confirmed the reproducibility of serum Fe concentration as a prognostic criterion in cows with ACM. Our results showed a diagnostic cut-off value for serum $\mathrm{Fe}$ concentrations of $<31.5 \mu \mathrm{g} / \mathrm{dL}$ based on ROC curves in order to identify cows with a poor prognosis. The AUC for serum Fe concentration was 0.781 , and the sensitivity and specificity of the proposed diagnostic cut-off value for serum Fe concentrations were $73.3 \%$ and $94.1 \%$, respectively. The accuracy of prognostic criteria of serum Fe concentration in this study was moderate, as in a previous study (Shimamori 


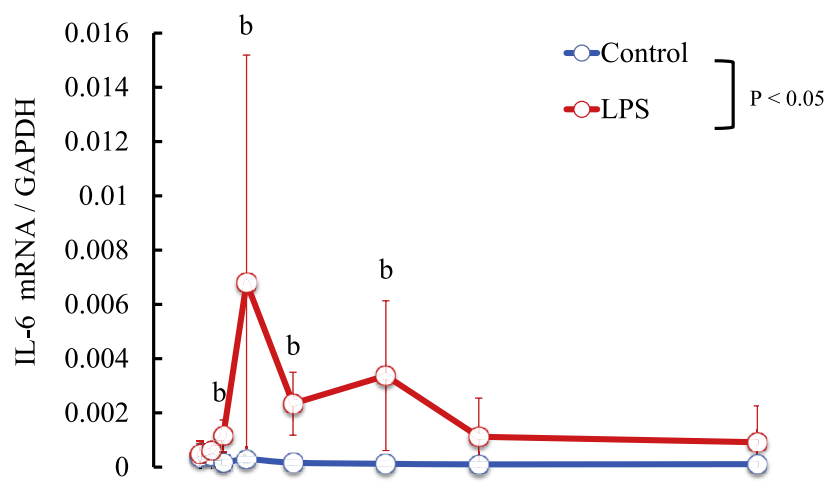

and hepcidin mRNA in hepatic tissues in cattle that received endotoxin were maintained from 2 to $8 \mathrm{~h}$ after endotoxin challenge, and serum $\mathrm{Fe}$ concentration decreases were observed at $24-48 \mathrm{~h}$ after endotoxin challenge. It should be noted that decreases in serum Fe concentration are difficult to confirm within $8 \mathrm{~h}$ after LPS administration. In contrast, our result demonstrated that significant decreases in serum $\mathrm{Fe}$ concentration cannot be confirmed until $24 \mathrm{~h}$ after LPS administration. Our confirmation is in good agreement with the results obtained in the study of Erskine and Bartlett (1993): serum Fe concentration decreases were observed at 20-24 h after intramammary infection with E. coli.

In the present study, we found that the accuracy of serum $\mathrm{Fe}$ concentration as a prognostic criterion in cows with ACM was moderate, as in a previous study. However, the reproducibility of serum $\mathrm{Fe}$ concentration as a prognostic criterion was not satisfactory in this study. As one of the reasons for this, we demonstrated that a decrease in serum $\mathrm{Fe}$ concentration did not occur immediately after endotoxin shock. In addition, we revealed that it took about $24 \mathrm{~h}$ for the serum Fe concentration to decrease in cattle with endotoxaemia. Because in cows with clinical ACM it is difficult to know the time course after infection, the alteration in serum Fe concentrations alone may be an insufficient prognostic criterion. Our results indicated that serum Fe measurement in conjunction with the clinical signs (Wenz et al., 2001) and other inflammatory markers (Hagiwara et al., 2001; Vels et al., 2009) could be useful prognostic criteria for ACM in cows.

The present study has a few limitations. First, some factors unrelated to inflammation also alter serum Fe concentrations in cows. Because nutritional conditions, such as hypoproteinaemia (Jones and Allison, 2007), affect blood Fe concentrations, the influence of farm management on cows cannot be ignored in clinical cases. Second, there are high variations in our data. Although our data had sufficient $P$ values, further validation in a larger cohort is necessary.

\section{ACKNOWLEDGEMENT}

This study was supported by the Rakuno Gakuen University Research Fund (2019).

\section{criterion in cows with ACM was not satisfactory.} reproducibility of serum $\mathrm{Fe}$ concentration as a prognostic

In Study 2, we clarified the variations in serum Fe concentrations in cattle that received endotoxin. Endotoxin activates toll-like receptor 4 signalling, which increases the production of IL-6 by macrophages (Constante et al., 2006). The effects of inflammation on Fe metabolism are mediated by the IL-6-hepcidin axis: IL-6 stimulates hepcidin expression via the Janus Kinase (JAK)/signal transducer and activator of transcription 3 (STAT 3) pathways. Inflammation also induces activin $\mathrm{B}$, which stimulates bone morphogenetic protein (BMP)-6/small mothers against decapentaplegic (SMAD) pathway, leading to hepcidin expression synergistically with the IL-6 and STAT3 pathway (Ganz, 2013). In our study, high expression of IL-6

\section{REFERENCES}

Akobeng, A. K. (2007): Understanding diagnostic test 3: receiver operating characteristic curves. Acta Paediatr. 96, 644-647.

Andriopoulos, B., Jr., Corradini, E., Xia, Y., Faasse, S.A., Chen, S., Grgurevic, L., Knutson, M. D., Pietrangelo, A., Vukicevic, S., Lin, H. Y. and Babitt, J. L. (2009): BMP6 is a key endogenous regulator of hepcidin expression and iron metabolism. Nat. Genet. 41, 482-487.

Baydar, E. and Dabak, M. (2014): Serum iron as an indicator of acute inflammation in cattle. J. Dairy Sci. 97, 222-228. 
Borges, A. S., Divers, T. J., Stokol, T. and Mohammed, O. H. (2007): Serum iron and plasma fibrinogen concentrations as indicators of systemic inflammatory diseases in horses. J. Vet. Intern. Med. 21, 489-494.

Cherayil, B. J. (2011): The role of iron in the immune response to bacterial infection. Immunol. Res. 50, 1-9.

Cherayil, B. J., Ellenbogen, S. and Shanmugam, N. N. (2011): Iron and intestinal immunity. Curr. Opin. Gastroenterol. 27, 523528.

Constante, M., Jiang, W., Wang, D., Raymond, V. A., Bilodeau, M. and Santos, M. M. (2006): Distinct requirements for Hfe in basal and induced hepcidin levels in iron overload and inflammation. Am. J. Physiol. Gastrointest. Liver Physiol. 291, G229-G237.

Erskine, R. J. and Bartlett, P. C. (1993): Serum concentrations of copper, iron, and zinc during Escherichia coli-induced mastitis. J. Dairy Sci. 76, 408-413.

Ganz, T. (2013): Systemic iron homeostasis. Physiol. Rev. 93, 17211741.

Hagiwara, K., Yamanaka, H. Hisaeda, K., Taharaguchi, S., Kirisawa, R. and Iwai, H. (2001): Concentrations of IL-6 in serum and whey from healthy and mastitic cows. Vet. Res. Commun. 25, 99-108.

Hillerton, J. E. and Berry, E. A. (2005): Treating mastitis in the cow - a tradition or an archaism. J. Appl. Microbiol. 98, 1250-1255.

Hirayama, T. and Nagasawa, H. (2017): Chemical tools for detecting Fe ions. J. Clin. Biochem. Nutr. 60, 39-48.

Hogan, J. and Smith, K. L. (2003): Coliform mastitis. Vet. Res. 34, 507-519.

Jones, M. L. and Allison, R. W. (2007): Evaluation of the ruminant complete blood cell count. Vet. Clin. North Am. Food Anim. Pract. 23, 377-402.

Lohuis, J. A., Schukken, Y. H., Verheijden, J. H., Brand, A. and Van Miert, A. S. (1990): Effect of severity of systemic signs during the acute phase of experimentally induced Escherichia coli mastitis on milk production losses. J. Dairy Sci. 73, 333-341.

National Research Council (US) (2011): Committee for the Update of the Guide for the Care and Use of Laboratory Animals. 8th edition. National Academies Press, Washington, D.C. pp. 1124.

Nemeth, E., Valore, E. V., Territo, M., Schiller, G., Lichtenstein, A. and Ganz, T. (2003): Hepcidin, a putative mediator of anemia of inflammation, is a type II acute-phase protein. Blood 101, 2461-2463.

Ong, S. T., Ho, J. Z., Ho, B. and Ding, J. L. (2006): Iron-withholding strategy in innate immunity. Immunobiology 211, 295-314.

Przybylowski, P., Malyszko, J. S., Macdougall, I. C. and Malyszko, J. (2013): Iron metabolism, hepcidin, and anemia in orthotopic heart transplantation recipients treated with mammalian target of rapamycin. Transplant. Proc. 45, 387-390.

Shimamori, T., Noda, J., Tsukano, K., Sera, K., Yokota, H., Koiwa, M., Suzuki, T. and Suzuki, K. (2017): Particle-induced X-ray emission analysis of serum trace and major elements in cattle with acute coliform mastitis. Jpn. J. Vet. Res. 65, 29-37.

Vels, L., Røntved, C. M., Bjerring, M. and Ingvartsen, K. L. (2009): Cytokine and acute phase protein gene expression in repeated liver biopsies of dairy cows with a lipopolysaccharide-induced mastitis. J. Dairy Sci. 92, 922-934.

Ward, C. G., Bullen, J. J. and Rogers, H. J. (1996): Iron and infection: new developments and their implications. J. Trauma. 41, 356-364.

Wenz, J. R., Barrington, G. M., Garry, F. B., McSweeney, K. D., Dinsmore, R. P., Goodell, G. and Callan, R. J. (2001): Bacteremia associated with naturally occurring acute coliform mastitis in dairy cows. J. Am. Vet. Med. Assoc. 219, 976-981.

Zhang, A. S. (2010): Control of systemic iron homeostasis by the hemojuvelin-hepcidin axis. Adv. Nutr. 1, 38-45. 